\title{
Pathway of Suspected-COVID-19 Patients From French Emergency Departments During The First Outbreak: A Prospective Controlled Cohort Study
}

marion DOUPLAT ( $\nabla$ marion.douplat@chu-lyon.fr)

Hospices Civils de Lyon

Antoine GAVOILLE

Hospices Civils de Lyon

Fabien SUBTIL

Hospices Civils de Lyon

Julie HAESEBAERT

Hospices Civils de Lyon

Laurent JACQUIN

Hospices Civils de Lyon

Guillaume DURAND

Hôpital de Villefranche

Jean- Christophe LEGA

Hospices Civils de Lyon

Thomas PERPOINT

Hospices Civils de Lyon

Véronique POTINET

Hospices Civils de Lyon

Alain SIGAL

Hospices Civils de Lyon

Julien BERTHILLER

Hospices Civils de Lyon

Nathalie PERRETON

Hospices Civils de Lyon

Karim TAZAROURTE

Hospices Civils de Lyon

\section{Research Article}

Keywords: COVID-19, mortality, hospitalization, emergency department 
Posted Date: March 26th, 2021

DOI: https://doi.org/10.21203/rs.3.rs-332505/v1

License: (c) (i) This work is licensed under a Creative Commons Attribution 4.0 International License. Read Full License 


\section{Abstract}

\section{Background}

To describe the clinical characteristics, management, and outcome of patients admitted in French emergency departments (EDs) for COVID-19 suspicion.

\section{Methods}

A prospective, multicenter, observational study was conducted in 4 EDs. Adult patients ( $\geq 18$ years) admitted in EDs between March 6, 2020 and May 10, 2020, hospitalized, and who were presenting symptoms evocative of COVID-19 were included. The clinical features, management, and prognosis of patients was compared according to their confirmed COVID-19 status.

\section{Results}

A total of 2,686 patients were included, among them 760 (28.3\%) were COVID-19 positive. Among the latter, the mean \pm SD age was $71.5 \pm 16.5$ years. A total of $364(48.0 \%)$ positive patients had hypertension, $228(30.0 \%)$ had chronic cardiac disease, $186(24.5 \%)$ had diabetes, $126(16.6 \%)$ were obese, and 114 (15.0\%) had chronic respiratory disease. The proportion of patients admitted in intensive care units (ICU) was higher among COVID-19 positive patients $(185,24.3 \%)$ compared to COVID-19 negative patients $(206,10.7 \% ; p<0.001)$ and they required mechanical ventilation more frequently $(89$, $11.9 \%$ vs $37,1.9 \% ; p<0.001)$. The median [IQR] length of hospital stay was longer among COVID-19positive patients (10 [6-15] vs 6 [2-11] days; $p<0.001)$. The in-hospital mortality was significantly higher among COVID-19 positive patients $(139,18.3 \%$ vs $149,7.7 \%$; $p<0.001)$.

\section{Conclusions}

This study suggests that among the COVID-19 suspected patients admitted in EDs and requiring a hospitalization, the management was different according to the confirmed COVID-19 status and required different resources in terms of ICU beds and ventilator support.

\section{Background}

The coronavirus disease 2019 (COVID-19) pandemic was declared on March 11, 2020 by the World Health Organization [1-3]. From December 31, 2019 to January, 2021, 98,280,844 cases were confirmed worldwide, among which 32,848,998 in Europe [4]. France has been one of the most impacted country in the world by the COVID-19 pandemic, and counted 3,130,629 confirmed cases and 74,800 deaths during this period [5]. The first outbreak started in France at the beginning of March, 2020 and a containment was officially established from March 17 to May 11, 2020 [5].

The French emergency departments (EDs) were on the frontline during the COVID-19 outbreak and oversaw patient triage - based on COVID-19 suspicion - as they were in other countries [6-7]. The role of 
ED in patient triage was crucial in order to contain and isolate the suspected COVID-19 cases. The need of a dynamic in the patient flow processing has been highlighted [8] and several hospital emergency management plans have been proposed including before-admission triage center [9-11]. Several studies have focused on the outcomes of patients during the COVID-19 pandemic but a few have investigated the management of COVID-19 cases from the perspective of EDs [12-14]. However, the need to understand how to manage these patients in EDs is a necessity to avoid the overcrowding, to guarantee the safety of the healthcare workers, to anticipate the future need for beds and staff members, and to be able to continue caring for non-COVID-19 patients [12,15].

As the number of COVID-19 cases is rapidly increasing in France at the beginning of March, 2020 we have set up the COVID-ER cohort study. It aimed to provide an exhaustive description over time of the pathway and outcome of patients admitted in French EDs for COVID-19 suspicion from March to May, 2020. The characteristics associated with COVID-19 diagnosis confirmation and prognosis, including ICU admission and all-cause mortality, were described.

\section{Methods}

\section{Study design and setting}

A multicenter prospective observational cohort study was conducted between the March 6 and May 10, 2020 in 4 French EDs comprising 3 universities (Edouard Herriot, Lyon Sud and Croix Rousse Hospital) and 1 general hospital (Villefranche Hospital) around Lyon. The Lyon urban area is the second largest in France and counts 1.6 millions of people. The three university EDs are in urban hospitals and count more than 40,000 annual ED visits for two of them and 80,000 for the third. The ED of the general hospital is suburban and counts 50,000 annual ED visits. This study complied with the Declaration of Helsinski, was approved by both the Institutional Ethics Committee of Hospices Civils of Lyon ( $\left.{ }^{\circ} 20-47\right)$ and the National Committee for Data Protection ( ${ }^{\circ}$ 20-090), as requested by the French law. The present manuscript met the STROBE statement [16]. According to French legislation, no written consent was required but only an oral consent approved by the Ethics Committee of Hospices Civils of Lyon ( $\left.\mathrm{N}^{\circ} 20-47\right)$ and the National Committee for Data Protection ( $\left.n^{\circ} 20-090\right)$. All patients were informed that their data were being collected as part of the COVID-ER study via a written information notice and they could object to the collect of their information.

\section{Selection of Participants}

All adult patients ( $\geq 18$ years) presenting to the ED for COVID-19 suspicion (with symptoms evocative of severe acute respiratory syndrome coronavirus (SARS-CoV)-2 infection) and requiring hospitalization were included. These symptoms and the criteria of hospitalization are detailed in Supplementary material 1 (S1). Were excluded the COVID-19-suspected patients who did not require hospitalization because there were sent back home without testing due to the limited availability of PCR tests in France at the time of the study. 
Patients were tested for SARS-CoV-2 infection using reverse transcriptase polymerase chain reaction (RTPCR) of respiratory samples. The RT-PCR assays were performed using the RdRp IP2-IP4 primers and probes of the Institut Pasteur protocol, which is used in France for SARS-CoV-2 detection. This protocol, detecting two targets in the RdRp gene, was adapted on the Panther Fusion ${ }^{\circledR}$ (Hologic) molecular system for high throughput diagnostic. A confirmed case of COVID-19 was defined as a test positive for the detection of SARS-CoV-2. In case of multiple sampling during hospitalization, the final virological diagnostic was classified as positive if one of the samples was tested positive.

\section{Data Collection and Processing}

All data were collected from electronic medical records and were for each included patient: demographic characteristics (age, sex, living place, functional independence, health care workers status) and clinical characteristics (symptoms and vital signs at ED admission, size, weight, chronic underlying comorbidities, smoking status). The chronic underlying diseases considered were as follows: hypertension, diabetes, clinical heart failure (NYHA functional class III or IV), obesity (body mass index $[\mathrm{BMI}] \geq 30$ ), chronic respiratory disease defined as chronic restrictive or obstructive pulmonary disease, chronic kidney disease (glomerular filtration rate $[\mathrm{GFR}]<90 \mathrm{ml} / \mathrm{min}$ ), chronic neurological disorder, chronic hematological disease, immunosuppression, transplant, cirrhosis, dementia (if it had been documented by a Mini-Mental State Examination score under 24), malignancy (defined as current malignancy with or without metastasis), psychosis, and human immunodeficiency virus (HIV) infection. Laboratory findings (other viral and bacterial infection) and radiology findings (chest computed tomographic [CT] scan) were also collected. A CT-scan was considered positive for COVID-19 if there were features evocative of COVID19: ground glass opacity, crazy paving, sub-pleural bands of consolidations, reversed halo sign, and lung consolidations.

The vital status was collected in EDs and during hospitalization for the whole cohort. We also collected patient management and pathway: destination from EDs (intensive care units (ICU) conventional hospitalization), secondary admission from conventional hospitalization to ICU, ventilator support, decision of withholding or withdrawing life-sustaining treatments, re-hospitalization within 30 days after discharge.

\section{Primary Data Analysis}

Continuous variables were expressed as mean \pm standard-deviation (SD), or median [interquartile range, IQR] for duration, and categorical variables as count (percentage). Comparisons of outcomes between the COVID-19 positive and COVID-19 negative groups were performed using logistic regression for binary outcomes, and using linear regression with logarithmic transformation for delays. Multivariate analyses were performed: the effect of the COVID-19 status on the outcomes was adjusted for age, sex, number of comorbidities, and loss of autonomy. Unless specified otherwise, p-values reported correspond to the ones of multivariate analyses. The sample sizes and percentages over the study period were described using smoothed curved obtained using a LOESS algorithm. The changes in the percentage of death 
between age categories was compared between the COVID-19 positive and COVID-19 negative groups using a logistic regression model, testing the interaction between the age and group. P-values were considered significant below 0.05. Analyses were performed using R, version 3.6.1. (R Core Team (2019), Vienna, Austria, https://www.R-project.org/).

\section{Results}

From March 6, 2020 to May 10, 2020, 20,341 patients were admitted in the participating EDs, 7,199 (35.4\%) were hospitalized, 2,789 of whom were suspected of SARS-CoV-2 infection. A total of 103 patients were not included in the study due to missing RT-PCR test. Among the 7,199 admitted patients, 2,686 (37.3\%) were tested and 760/2,686 (28.3\%) tests were positive. The flow chart is detailed on Figure 1.

Patient characteristics according to the COVID-19 status

The mean \pm SD age of COVID-19 positive patient was $71.5 \pm 16.5$ years, $618(81.6 \%)$ were coming from home and 119 (15.7\%) from long-term care facilities. Hypertension was found in 364 (48.0\%) COVID-19 positive patients, chronic cardiac disease in 228 (30.0\%), diabetes in 186 (24.5\%), obesity in 126 (16.6\%), and chronic respiratory disease in 114 (15.0\%). Oxygen was required upon arrival at the EDs for 179 (23.6\%) COVID-19 positive patients, and for 353 (18.3\%) COVID-19 negative patients. A total of 215 (30.6\%) COVID-19 positive patients went to the EDs more than 7 days after symptom onset (315 (19.0\%) COVID-19 negative patients did) and 105 (15.0\%) during the first 24 hours after symptom onset (613 (36.9\%) COVID-19 negative patients did). Fever was encountered in 536 (70.5\%) COVID-19 positive patients, dyspnea in 494 (65.0\%), cough in 420 (55.3\%), and weakness in 399 (52.5\%). Bacterial coinfection was found in 57 (9.3\%) COVID-19 positive patients and 221 (14.6\%) in COVID-19 negative patients. A total of 454 (59.7\%) COVID-19 positive patients had a CT-scan evocative of COVID-19 (Table 1).

\section{Outcomes of patients}

The proportion of patients admitted in ICU directly from ED was significantly higher among COVID-19 positive patients $(86,11.3 \%)$ compared to COVID-19 negative patients $(162,8.4 \% ; p=0.036)$, and the risk of ICU admission directly from ED was greater with a positive COVID-19 status (univariate analysis: odd ratio $(\mathrm{OR})$ [95\% confidence interval, $\mathrm{Cl}]=1.34$ [1.00; 1.83$], \mathrm{p}=0.020$; multivariate analysis: $\mathrm{OR}[95 \% \mathrm{Cl}]=$ 1.34 [1.00; 1.78], $p=0.048$ ). Similarly, the proportion of patients secondarily admitted in ICU was significantly higher among COVID-19 positive patients $(99,14.7 \%)$ compared to COVID-19 negative patients $(44,2.5 \%$; $\mathrm{p}<0.001)$, and the risk of secondary ICU admission was greater with a positive COVID19 status (univariate analysis: OR $[95 \% \mathrm{Cl}]=6.80[4.74 ; 9.91], \mathrm{p}<0.001$; multivariate analysis: OR [95\%Cl] $=6.11$ [4.20; 9.03], p < 0.001). Overall, 185 (24.3\%) COVID-19 positive patients were admitted in ICU, and $206(10.7 \%)$ COVID-19 negative patients were $(p<0.001)$. The use of ventilation support - more specifically, the use of invasive mechanical ventilation and nasal high-flow nasal oxygen therapy - was significantly more frequent among COVID-19 positive patients $(89,11.9 \%$ and $135,18.1 \%$, respectively) 
compared to COVID-19 negative patients $(37,1.9 \%$ and $41,2.2 \%$, respectively; $p<0.001$ for both techniques). The median [IQR] length of stay in hospital was significantly longer for COVID-19 positive patients (10 [6 - 15] days) compared to COVID-19 negative patients (6 [2 - 11] days; $p<0.001)$. Mortality during hospitalization was significantly higher among COVID-19 positive patients $(139,18.3 \%)$ compared to COVID-19 negative patients $(149,7.7 \% ; \mathrm{p}<0.001)$, and the mortality risk was greater with a positive COVID-19 status (univariate analysis: OR $[95 \% \mathrm{Cl}]=2.67$ [2.08; 3.42], $\mathrm{p}<0.001$; multivariate analysis: OR $[95 \% \mathrm{Cl}]=3.05[2.22 ; 3.99], \mathrm{p}<0.001)$. Similarly, the number of decisions of withholding or withdrawing life-sustaining treatments in EDs and during hospitalization was greater concerning COVID-19 positive patients $(53,7.0 \%$ and $151,19.9 \%$, respectively) than concerning COVID-19 negative patients $(90,4.7 \%$ and $221,11.5 \% ; p=0.001$ and $p<0.001$, respectively). After hospital discharge, a greater proportion of COVID-19 positive patients went into a rehabilitation department before returning home $(157,28.3 \%)$ compared to COVID-19 negative patients $(245,15.1 \%$; $p<0.001$; Table 2$)$.

\section{Patient pathway from the emergency departments}

The proportion of patients who died during conventional hospitalization and in ICU was higher among COVID-19 positive patients $(92,13.7 \%$ and $46,24.9 \%$, respectively) compared to COVID-19 negative patients (109, 6.2\% and 32, 15.6\%; $p<0.001$ and $p=0.016$, respectively). Among the 673 COVID-19 positive patients who were in conventional hospitalization, $53(7.9 \%)$ were discharged early ( $<48 \mathrm{~h})$ from hospital, compared to 408 (23.9\%) COVID-19 negative patients. The patient pathway of COVID-19 positive and COVID-19 positive patients is detailed in Figure 2.

\section{Changes in terms of care over the study period among COVID-19 positive patients}

The number of COVID-19 positive patients rapidly increased over the course of March, 2020 with a peak number reached on March 27, 2020 (Fig 3). The number of patients admitted to the ICU decreased since the beginning of the study. The death rate was stable over the study period. However, before April 15, 2020 patients requiring ICU and intubation were more likely to die whereas after April 15, 2020 patients who did not go into ICU were more likely to die (Fig 4). The number of decisions of withholding or withdrawing life-sustaining treatments was stable over time. The age of COVID-19 positive patients admitted to EDs was stable during the study period. The age of the deceased COVID-19 positive patients increased during the second period of the study (supplemental material S2 and S3).

\section{Patient outcomes according to age}

No COVID-19 positive patients over 90 was concerned by hospitalisation of less than 48 hours, but about $19.2 \%$ (39) of COVID-19 negative patients over 90 were. The ICU admission concerned mostly COVID-19 positive patients under 80 . The proportion of death was higher in higher-aged groups, this proportion was even higher among COVID-19 positive patients (33.6\% of death for patients over 80 ) compared to COVID19 negative patients ( $11.9 \%$ of death for patients over $80 ; p=0.014$; Fig 5 ).

\section{Discussion}


This study highlights the pathway and the outcomes of suspected COVID-19 patients during the first outbreak from EDs. The present study emphasized that the management and the outcomes of suspected COVID-19 patients were different depending on their COVID-19 status. COVID-19 positive patients required more resource in terms of ICU admission, rehabilitation admission, ventilator support, and stayed longer in the hospital than COVID-19 negative patients. Mortality was also higher among COVID-19 positive patients, this difference was even greater among patients over 80 . The results presented herein also suggested that the profile of patients admitted to the EDs, and who die, differed over the study period. Before April 15 ${ }^{\text {th }}$, COVID-19 positive patients were younger and were more likely to be admitted to ICU, whereas after April $15^{\text {th }}$, they were older, more likely to die in general wards, and were concerned by more decisions of withholding and withdrawing life-sustaining treatments.

The characteristics of the COVID-19 positive patients of the present study broadly reflect the ones reported in other studies, especially in terms of symptoms and co-morbidities $(2,3,17-19)$. The rate of obesity was low, about two times lower than in the United States of America (USA)). These trends are consistent with the prevalence of obesity in the general population in France and the United States (20). COVID-19 positive patients had a higher median age than patients in China (2), USA (7), and Italy (18), but a similar median age compared to UK patients (19). These differences may be explained by the different recruitment methods that were used. Herein, ambulatory patients, who are most often younger, were not included, but all hospitalized patients (corresponding to older patients who are more vulnerable and frail) were included.

The proportion of COVID-19 positive patients admitted to ICU was higher previous studies conducted in USA (New York) $(12,18)$ and UK (19). Several factors may explain these differences. First, the availability of ICU beds is different between countries. At the time of the study, the study ICUs were not overloaded but still reached maximum capacities despite a $30 \%$ increase in the number of beds during the first COVID-19 outbreak. Second, secondary ICU admissions were included herein in the follow-up and were more numerous than primary admissions, whereas they were not always considered in the previously mentioned studies. They correspond to patients who have worsened secondarily within an average of 1 to 2 days. This point has already been emphasized by Singer et al. who have insisted on the need to take secondary ICU admissions into account in order to better estimate ICU capacities. Indeed, they demonstrated that for every 100 persons under investigation who are admitted to the hospital, 9 will require immediate ICU and another 12 will require ICU or invasive mechanical ventilation within 2 to 3 days (12). Finally, the use of mechanical ventilation for COVID-19 positive patients was similar to other studies $(18,19)$ whereas the rate of nasal high-flow nasal oxygen therapy and non-invasive ventilation were higher in our study, suggesting that practices differ across countries (22).

The mortality rated observed herein was lowered compared the one reported in the UK population (19), but not different from the one reported in the US $(18,21)$ or in Italy $(17)$. This could be due to differences in healthcare systems between the UK and Europe and in the proportion of ICU beds to hospital beds, as it has been suggested (19). In addition, patient comorbidities and drug exposure (included glucocorticoids) may differ between cohorts. We showed herein that COVID-19 positive patients over 80 benefited from 
very few ICU admissions and mechanical ventilation and died more often than the COVID-19 negative patients. This observation has been supported by other studies $(12 ; 19)$. An interesting point is the fact that, during the second period of the study, patients who died were not admitted into ICU and were older, suggesting the presence of clusters in retirement homes at this time of the outbreak. Retirement homes were also affected in the US as a similar proportion of patients coming from retirement homes has been reported (12).

The decisions of withholding and withdrawing life-sustaining treatments during the COVID-19 pandemic have been rarely studied because of the difficulty to collect data regarding the a priori decided level of care (19). In the present study, a high prevalence of these decisions concerning COVID-19 positive patients was reported. However, there was no difference in the amount of these decisions prior to death between COVID-19 positive and negative patients. In our opinion, this can be explained by the fact that the COVID-19 health crisis led healthcare teams to anticipate the potential aggravation of patients. Indeed, it has been previously shown that there was little anticipation regarding end-of-life decisions in the EDs and that the management such decisions should be improved (23-24). The decision-making process of these decisions is especially difficult in the context of emergency medicine because of lack of time, absence of anticipation in chronic diseases, and restrictions of access to families in EDs due to the pandemic. Therefore, the healthcare teams face several challenges with these decisions for which the consequences are not well assessed (25).

Understanding what happened during this first outbreak in the EDs is crucial to anticipate other health crises. Emergency departments are on the front line in this type of crises and must also manage potential COVID-19 patients that contribute to the health care burden and ED overcrowding. In Australia, despite the low rate of COVID-19 positive cases, an increasing number of ED patients are likely to require isolation because the testing criteria are broadened (26). The same statement has been reported in the ED sin New York where more than two thirds of all the admissions were patients suspected of COVID-19 (12). In our opinion, this first outbreak helped us to better quantify to the need for ICU beds and to underline the importance of flexible organizations to quickly adapt conventional and ICU capacities to the incoming flow of COVID-19 positive patients.

The present cohort was composed of a large sample of patients admitted in ED for COVID-19 suspicion, during the first COVID-19 outbreak in France, over a period that included the totality of the first containment in France. The region of Lyon was one of the most impacted during the first outbreak, after the Great East region and the region of Paris, which provided an interesting viewpoint regarding the management of the COVID-19 pandemic in EDs. Nevertheless, this study has several limitations. First, we included a majority of university hospitals, which had a greater capacity of ICU beds and which certainly has influenced the ICU admission rate. Second, the study was conducted only during the first outbreak and over a reduced period. Since then, practices have changed: the test criteria are broader, corticosteroids (mainly dexamethasone) have been introduced systematically for the most critical patients, and there is an increase in physician expertise. Finally, despite the use of multivariable model, we cannot excluded residual confounders. 


\section{Conclusion}

In conclusion, COVID-19 positive patients require more resources in ICU beds and their management is different compared to COVID-19 negative patients. These differences must be considered in order to adapt the necessary resources. Understanding the profile of patients and their pathway in the EDs during the first outbreak of COVID-19 is essential in order to improve hospital practices and anticipate the next waves.

\section{Declarations}

- Ethics approval and consent to participate: The study was approved by the ethic committee of the University Hospital of Lyon on April 17, 2020 (№20-47).

- Consent for publication: During the study period, patients were informed that their data were being collected as part of the COVID ER study via a written information notice. They could object to the collection of their information in accordance with current French legislation.

- Availability of data and materials: The datasets used and/or analyzed in the present study are available upon reasonable request to the corresponding author. Data transfer must be approved by the Comission nationale de l'informatique et libertés (CNIL: French commission on data privacy).

- Competing interests: The author(s) declare no potential conflict of interest with respect to the research, authorship, and/or publication of this manuscript.

- Funding: The Hospices Civils of Lyon made research staff available for data collection during the study period.

- Authors' contributions: MD conceived the study and designed the study. JB and NP supervised the conduct of the study and data collection, undertook recruitment of participating centers and patients, and managed the data, including quality control. FS and AG provided statistical advice on study design and analyzed the data. MD drafted the manuscript, and all authors contributed substantially to its revision. MD takes responsibility for the manuscript as a whole.

- Acknowledgements: The authors acknowledge the support of the HCL Covid Task Force. We thank Claire-Angeline Goutard, Marine Alvès, Sofia Sebaoui, Roxane Bai, Lamia Azouzi, Ouazna Tassa, Laurie Herman, Sophie Hommey, Selma Baka, Hicham Kadura, Pauline Drouin and Jeanne Ragot for data collection. We also thank Hélène Boyer (Direction de la recherche clinique et de l'innovation, Hospices Civils de Lyon) for help in manuscript preparation.

\section{References}

1. WHO. WHO Director-General's opening remarks at the media briefing on COVID-19 - 11 March 2020. https://www.who.int/dg/speeches/ detail/who-director-general-s-opening-remarks-at-themediabriefing-on-covid-19--11-march-2020. 
2. Huang C, Wang Y, Li X, et al. Clinical features of patients infected with 2019 novel coronavirus in Wuhan, China. Lancet 2020;395:497-506.

3. Chen N, Zhou M, Dong X, et al. Epidemiological and clinical characteristics of 99 cases of 2019 novel coronavirus pneumonia in Wuhan, China: a descriptive study. Lancet 2020;395:507-13.

4. WHO. WHO coronavirus disease 2019 (covid-19) situation reports.

https://www.who.int/emergencies/diseases/novel-coronavirus-2019/situation-reports

5. Santé Publique France Infection au nouveau Coronavirus (SARS-CoV-2), COVID-19, France et Monde. https://www.santepubliquefrance.fr/dossiers/coronavirus-covid-19/coronavirus-chiffres-cles-etevolution-de-la-covid-19-en-france-et-dans-le-monde

6. Chung HS, Lee DE, Kim JK, Yeo IH, Kim C, Park J, Seo KS, Park SY, Kim JH, Kim G, Lee SH, Cheon JJ, Kim YH. Revised Triage and Surveillance Protocols for Temporary Emergency Department Closures in Tertiary Hospitals as a Response to COVID-19 Crisis in Daegu Metropolitan City. J Korean Med Sci. 2020 May 18;35(19):e189.

7. Wee LE, et al. Acad Emerg Med. 2020.Containing COVID-19 in the Emergency Department: The Role of Improved Case Detection and Segregation of Suspect Cases.

8. Tan RMR, Ong GY-K,Chong S-L,et al.. Dynamic adaptation to COVID-19 in a Singapore paediatric emergency department. Emerg Med J 2020;37:252-254

9. Cao Y, Li Q, Chen J, Guo X, Miao C, Yang H, Chen Z, Li C, Li L.Hospital Emergency Management Plan During the COVID-19 Epidemic. Acad Emerg Med. 2020 Apr;27(4):309-311.

10. Silvagni $E$, et al. How to organize an emergency department during the COVID-19 pandemic. J Popul Ther Clin Pharmacol. 2020.

11. Gilbert A, et al. Management of emergency department inflows during the COVID-19 outbreak in the CHU of Liege : efficiency of an advanced triage center. Rev Med Liege. 2020.

12. Singer AJ, Morley EJ, Meyers K, Fernandes R, Rowe AL, Viccellio P, Thode HC, Bracey A, Henry MC. Cohort of Four Thousand Four Hundred Four Persons Under Investigation for COVID-19 in a New York Hospital and Predictors of ICU Care and Ventilation. Ann Emerg Med. 2020 Oct;76(4):394-404.

13. O'Reilly GM, Mitchell RD, Rajiv P, Wu J, Brennecke H, Brichko L, Noonan MP, Hiller R, Mitra B, Luckhoff C, Paton A, Smit V, Santamaria MJ, Cameron PA. Epidemiology and clinical features of emergency department patients with suspected COVID-19: Initial results from the COVID-19 Emergency Department Quality Improvement Project (COVED-1). Emerg Med Australas. 2020 Aug;32(4):638-645.

14. Argenziano MG, Bruce SL, Slater CL, Tiao JR, Baldwin MR, Barr RG, Chang BP, Chau KH et al. Characterization and clinical course of 1000 Patients with COVID-19 in New York: retrospective case series. BMJ 2020 May 29;369:m1996.

15. Boserup B, McKenney M, Elkbuli A. The impact of the COVID-19 pandemic on emergency department visits and patient safety in the United States. Am J Emerg Med. 2020 Sep;38(9):1732-1736.

16. Von Elm E, Altman DG, Egger M, Pocock SJ, Gotzsche PC, Vandenbroucke JP. The Strengthening the Reporting of Observational Studies in Epidemiology (STROBE) Statement: guidelines for reporting observational studies. J Clin Epidemiol. 2008;61:344-9. 
17. Grasselli G, Zangrillo A, Zanella A, et al. Baseline Characteristics and Outcomes of 1591 Patients Infected With SARS-CoV-2 Admitted to ICUs of the Lombardy Region, Italy. JAMA. 2020;323(16):1574-1581.

18. Richardson S, Hirsch JS, Narasimhan M, et al, and the Northwell COVID-19 Research Consortium. Presenting characteristics, comorbidities, and outcomes among 5700 patients hospitalized with covid-19 in the New York City area. JAMA 2020. doi:10.1001/ jama.2020.6775

19. Docherty AB, Harrison EM, Green CA, Hardwick HE, Pius R, Norman L, Holden KA, Read JM, Dondelinger F, Carson G, Merson L, Lee J, Plotkin D, Sigfrid L, Halpin S, Jackson C, Gamble C, Horby PW, Nguyen-Van-Tam JS, Ho A, Russell CD, Dunning J, Openshaw PJ, Baillie JK, Semple MG; ISARIC4C investigators. Features of 20133 UK patients in hospital with covid-19 using the ISARIC WHO Clinical Characterisation Protocol: prospective observational cohort study. BMJ. 2020 May 22;369:m1985.

20. Hales CM, Carroll MD, Fryar CD, Ogden CL. Prevalence of Obesity Among Adults and Youth: United States, 2015-2016. NCHS Data Brief. 2017 Oct;(288):1-8. PMID: 29155689.

21. Petrilli CM, Jones SA, Yang J, Rajagopalan H, O'Donnell L, Chernyak Y, Tobin KA, Cerfolio RJ, Francois F, Horwitz LI. Factors associated with hospital admission and critical illness among 5279 people with coronavirus disease 2019 in New York City: prospective cohort study. BMJ. 2020 May 22;369:m1966. doi: 10.1136/bmj.m1966.

22. Cummings MJ, Baldwin MR, Abrams D, Jacobson SD, Meyer BJ, Balough EM, Aaron JG, Claassen J, Rabbani LE, Hastie J, Hochman BR, Salazar-Schicchi J, Yip NH, Brodie D, O'Donnell MR.

Epidemiology, clinical course, and outcomes of critically ill adults with COVID-19 in New York City: a prospective cohort study. Lancet. 2020 Jun 6;395(10239):1763-1770.

23. Douplat M, Berthiller J, Schott AM, Potinet V, Le Coz P, Tazarourte K, et al. Difficulty of the decisionmaking process in emergency departments for end-of-life patients. J Eval Clin Pract. 2019;25:1-7.

24. Douplat M, Fraticelli L, Claustre C, Peiretti A, Serre P, Bischoff M, Jacquin L, Freyssenge J, Schott AM, Tazarourte K, Frugier S, Khoury CEL, LAT group. Management of decision of withholding and withdrawing life-sustaining treatments in French EDs. Scand J Trauma Resusc Emerg Med. 2020;28(1):52.

25. Douplat M, Jacquin L, Frugier S, Tazarourte K, Le Coz P. Difficulty of the ethical decision-making process in withholding and withdrawing life-sustaining treatments in French EDs during COVID pandemic. Scand J Trauma Resusc Emerg Med. 2020 Aug 13;28(1):78.

26. O'Reilly GM, Mitchell RD, Wu J, Rajiv P, Bannon-Murphy H, Amos T, Brichko L, Brennecke H, Noonan MP, Mitra B, Paton A, Hiller R, Smit V, Luckhoff C, Santamaria MJ, Cameron PA. Epidemiology and clinical features of emergency department patients with suspected COVID-19: Results from the first month of the COVID-19 Emergency Department Quality Improvement Project (COVED-2). Emerg Med Australas. 2020 Oct;32(5):814-822.

\section{Tables}


Table 1. Clinical, Radiological, and laboratory characteristics of patients tested for SARS-CoV-2 infection 
Characteristics

COVID-19 negative

patients $(n=1,926,71.7 \%)$

COVID-19 positive

patients ( $n=760,28.3 \%$ )
All COVID-19 suspected patients

$(n=2,686)$

Age (years)

$70.8 \pm 18.6$

$71.5 \pm 16.5$

$71.0 \pm 18.0$

$330(43.4 \%)$

$1,306(48.6 \%)$

Female Sex

$976(50.7 \%)$

Living place $(n=2,653)$

618 (81.6\%)

2,197 (82.8\%)

Home

1,579 (83.3\%)

$119(15.7 \%)$

$345(13.0 \%)$

Long term care

$226(11.9 \%)$

$11(1.5 \%)$

65 (2.5\%)

facilities

Other hospital

$54(2.8 \%)$

$1(0.1 \%)$

$7(0.3 \%)$

$6(0.3 \%)$

$8(1.1 \%)$

$39(1.5 \%)$

Homeless

$31(1.6 \%)$

Other

\section{Referred to ED by \\ $(n=2,648)$}

Emergency medical

services (SAMU)

853 (45.1\%)

395 (52.1\%)

$1248(47.1 \%)$

497 (26.3\%)

201 (26.5\%)

$698(26.4 \%)$

General practitioners

295 (15.6\%)

$86(11.3 \%)$

381 (14.4\%)

Individual decision

$245(13.0 \%)$

$76(10.0 \%)$

$321(12.1 \%)$

Other

Loss of autonomy

$196(25.8 \%)$

602 (31.3\%)

$798(29.7 \%)$

Health care worker

$(n=2,558)$

$22(1.2 \%)$

$17(2.3 \%)$

$39(1.5 \%)$ 
Current smoker

$(n=2,002)$
296 (20.1\%)

$36(6.8 \%)$

$26.66(5.54)$

26.02 (6.09)

BMI $(n=2,427)$

$25.79(6.26)$
364 (48.0\%)

$228(30.0 \%)$

186 (24.5\%)

$114(15.0 \%)$

126 (16.6\%)

70 (9.2\%)

$28(3.7 \%)$

31 (4.1\%)

60 (7.9\%)

$34(4.5 \%)$

$7(0.9 \%)$

$10(1.3 \%)$

$11(1.4 \%)$

$6(0.8 \%)$

$6(0.8 \%)$

$1,283(47.9 \%)$

924 (34.5\%)

$657(24.5 \%)$

$596(22.2 \%)$

448 (16.7\%)

290 (10.8\%)

254 (9.5\%)

$234(8.7 \%)$

$192(7.2 \%)$

124 (4.6\%)

$58(2.2 \%)$

$54(2.0 \%)$

50 (1.9\%)

39 (2.0\%)

$22(1.1 \%)$

$11(0.6 \%)$
$28(1.0 \%)$

$17(0.6 \%)$

Psychosis

Transplant

HIV infection

\section{Vital signs at ED}

\section{admission}

Temperature $\left({ }^{\circ} \mathrm{C}\right)$

$(n=2,627)$

Oxygen saturation

$(n=2,620)$
$37.11 \pm 1.07$

$94.78 \pm 4.67$

353 (18.3\%)
$37.58 \pm 1.08$

$92.62 \pm 5.40$

$179(23.6 \%)$
$37.24 \pm 1.09$

$94.16 \pm 4.98$

$532(19.8 \%)$ 
Oxygen requirement

\section{Time since symptom onset}

$(n=2,361)$
$<24 h$
$<7$ days
$<15$ days
$\geq 15$ days

$613(36.9 \%)$

$105(15.0 \%)$

$718(30.4 \%)$

731 (44.1\%)

$382(54.4 \%)$

1,113 (47.1\%)

207 (12.5\%)

$181(25.8 \%)$

$388(16.4 \%)$

108 (6.5\%)

$34(4.8 \%)$

$142(6.0 \%)$

\section{Symptoms ( $\mathrm{n}$ from}

2,669 to 2,686 )

Fever

Dyspnea

Cough

Weakness

Diarrhea

Nausea or vomiting

Myalgia

Headache

Confusion

Abdominal pain

Anosmia

Rhinorrhea/congestion

Sore throat

Joint pain
$536(70.5 \%)$

$494(65.0 \%)$

$420(55.3 \%)$

399 (52.5\%)

$168(22.1 \%)$

87 (11.4\%)

$84(11.1 \%)$

$86(11.3 \%)$

80 (10.5\%)

57 (7.5\%)

51 (6.7\%)

$26(3.4 \%)$

$10(1.3 \%)$

$11(1.4 \%)$
1,452 (54.1\%)

$1,530(57.0 \%)$

1,179 (43.9\%)

$1,147(42.7 \%)$

419 (15.6\%)

$426(15.9 \%)$

$232(8.7 \%)$

$284(10.6 \%)$

278 (10.4\%)

$341(12.7 \%)$

85 (3.2\%)

$82(3.1 \%)$

$50(2.9 \%)$

$48(1.8 \%)$

$37(1.9 \%)$

$57(9.3 \%)$

$278(13.1 \%)$

Bacterial infection

$(n=2,126)$

$221(14.6 \%)$

$8(2.5 \%)$

$42(5.2 \%)$ 
Viral co-infection $\quad 34(6.8 \%)$

$(n=814)$

Type of Viral infection

Influenza A

Influenza B

VRS

Rhinovirus

Metapneumovirus

Adenovirus respiratory
$4(1.3 \%)$

$3(1.0 \%)$

$4(1.3 \%)$

$0(0.0 \%)$

$0(0.0 \%)$

$1(2.3 \%)$

$1(0.8 \%)$
$17(2.2 \%)$

$8(1.0 \%)$

$10(1.4 \%)$

$7(4.4 \%)$

$3(1.7 \%)$

$2(1.1 \%)$
Positive CT chest

$(n=1,686)$

Positive

Negative

Not done
237 (12.3\%)

$949(49.3 \%)$

$740(38.4 \%)$
454 (59.7\%)

$46(6.1 \%)$

$260(34.2 \%)$
$691(25.7 \%)$

995 (37.0\%)

$1,000(37.2 \%)$

Data are expressed as count (percentage), or mean \pm SD.

Abbreviations: BMI (body mass index) CT (chest computed tomographic), SD (standard deviation), VRS (respiratory syncytial virus), ED (emergency department), COVID-19 (coronavirus disease 2019)

Table 2: Outcomes of patients tested for SARS-CoV-2 infection. 


\section{Outcomes}

COVID-19

negative

patients

$(n=1,926)$
COVID-19

positive

patients

$(n=760)$

\section{Destination from ED}

Intensive care units

$86(11.3 \%)$

$0.036 *$

Conventional hospitalization

$162(8.4 \%)$

$673(88.6 \%)$

Died in ED

$1,756(91.2 \%) \quad 1(0.1 \%)$

$8(0.4 \%)$

Secondary admission from wards to intensive care units $(n=2,461)$

$99(14.7 \%)$

$44(2.5 \%)$

$<0.001$

$p=0.312 \#$

Time from ED admission to secondary admission to ICU (days) median [IQR 25-75] ( $\mathrm{n}=114)$

$1.72[0.82-$

$3.64]$

$2.76[0.96-$

4.53]

$185(24.3 \%)<0.001$

All transfers to ICU

$206(10.7 \%)$

\section{Ventilator support}

Invasive mechanical ventilation $(n=2,650)$

- $\quad$ Nasal high-flow oxygen $(n=2,648)$

- $\quad$ Non-invasive ventilation $(n=249)$
$89(11.9 \%)$

$<0.001$

$37(1.9 \%)$

$135(18.1 \%) \quad<0.001$

$41(2.2 \%)$
0.014

$94(4.9 \%)$

Length of hospital stay (days)

median [IQR 25-75] $(n=2,365)$

$6[2-11]$
$10[6-15]$

$$
<0.001
$$

Decision of withholding or withdrawing lifesustaining treatments:

In ED 


\begin{tabular}{|c|c|c|c|}
\hline - $\quad$ during hospitalization & $90(4.7 \%)$ & $53(7.0 \%)$ & 0.001 \\
\hline & $221(11.5 \%)$ & $151(19.9 \%)$ & $<0.001$ \\
\hline & & & $<0.001$ \\
\hline Death during hospitalization & $149(7.7 \%)$ & $139(18.3 \%)$ & \\
\hline $\begin{array}{l}\text { Death after a decision of withholding or } \\
\text { with }\end{array}$ & & & 0.778 \\
\hline & $105(70.5 \%)$ & $96(69.1 \%)$ & \\
\hline Time from ED admission to death (days) & & $8.80[3.66-$ & \\
\hline median [IQR 25-75] $(\mathrm{n}=276)$ & $\begin{array}{l}4.63[1.70- \\
10.84]\end{array}$ & & $<0.001$ \\
\hline Outcome after hospital discharge $(n=2,181)$ & & & $<0.001$ \\
\hline Return to home & $1,382(84.9 \%)$ & $397(71.7 \%)$ & \\
\hline Rehabilitation department & $245(15.1 \%)$ & $157(28.3 \%)$ & \\
\hline $\begin{array}{l}\text { Re-hospitalization within } \mathbf{3 0} \text { days after discharge } \\
(n=2,366)\end{array}$ & & $56(9.2 \%)$ & $<0.001$ \\
\hline & $293(16.7 \%)$ & & \\
\hline
\end{tabular}

p-values from multivariate analyses (adjusted for age, sex, number of comorbidities, loss of autonomy) unless specified\# univariate analysis with Wilcoxon rank sum test, ${ }^{\star}$ univariate analysis with Fisher's exact test.

Data are expressed as count (percentage), unless otherwise indicated Abbreviations: ED (emergency department), COVID-19 (coronavirus disease 2019) IQR (interquartile range), ICU (intensive care unit)

\section{Figures}




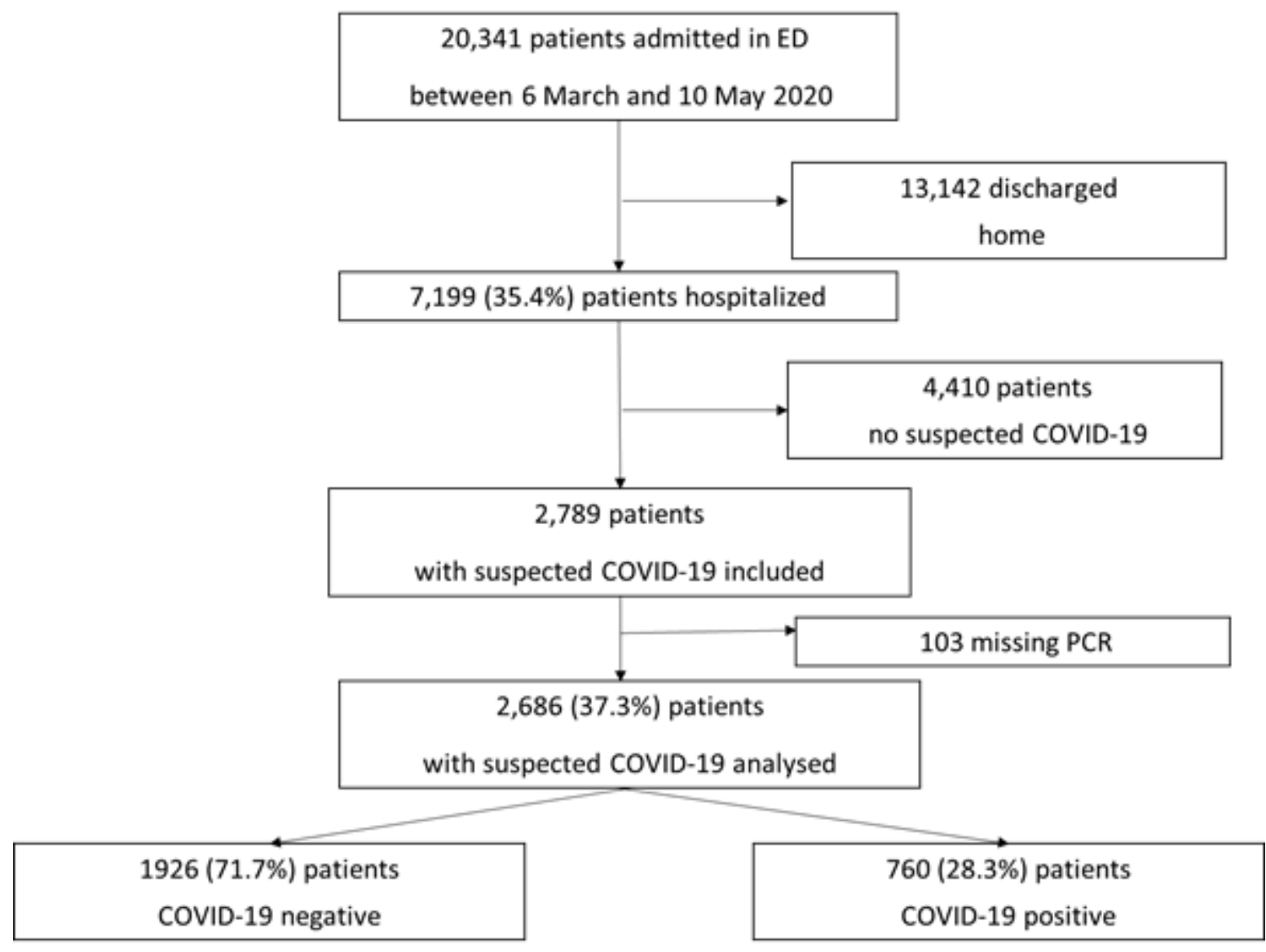

\section{Figure 1}

Trial profile of patients admitted to emergency departments during study period 

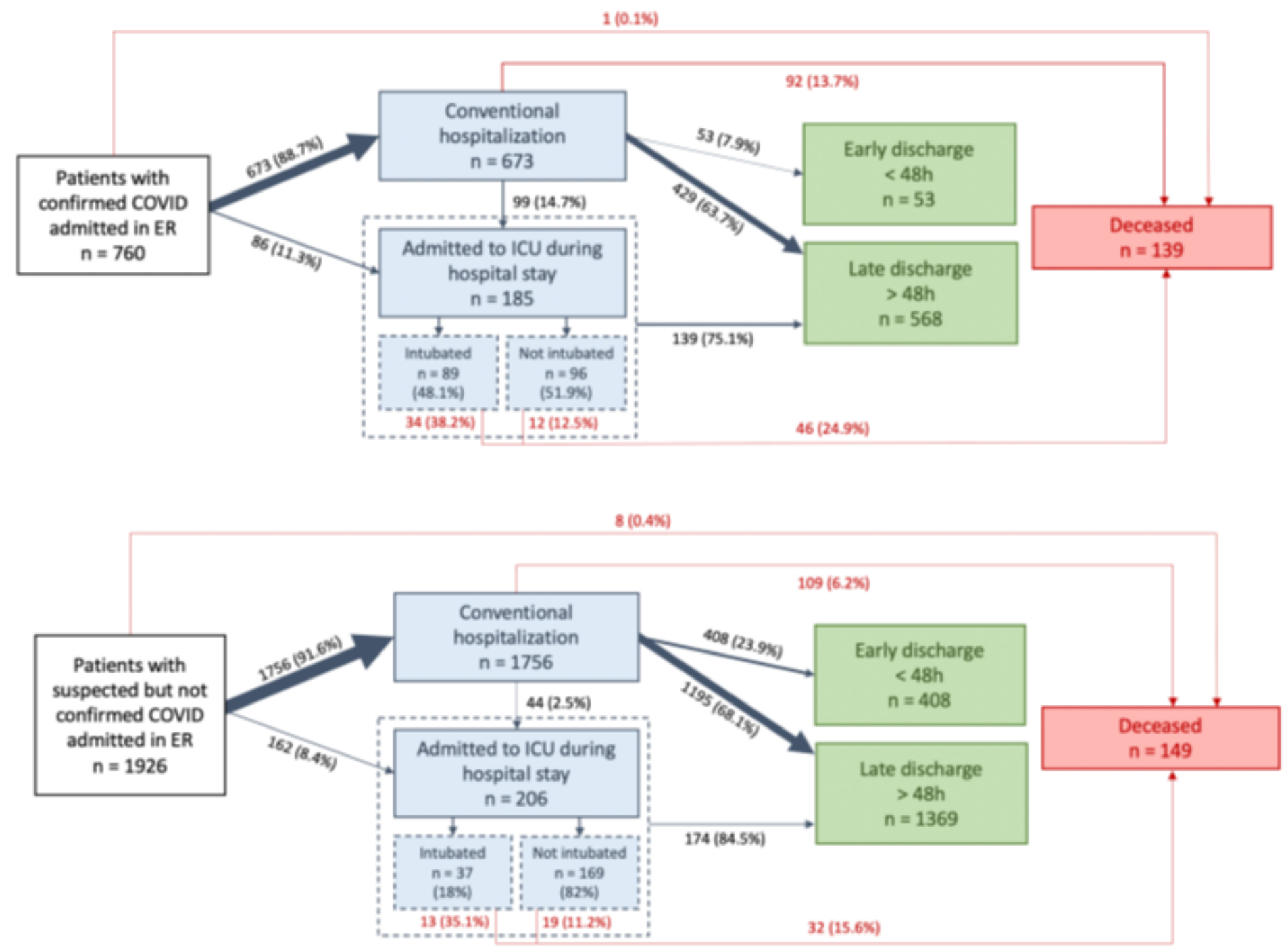

Figure 2

COVID-19 positive and COVID-19 negative patients' pathway 


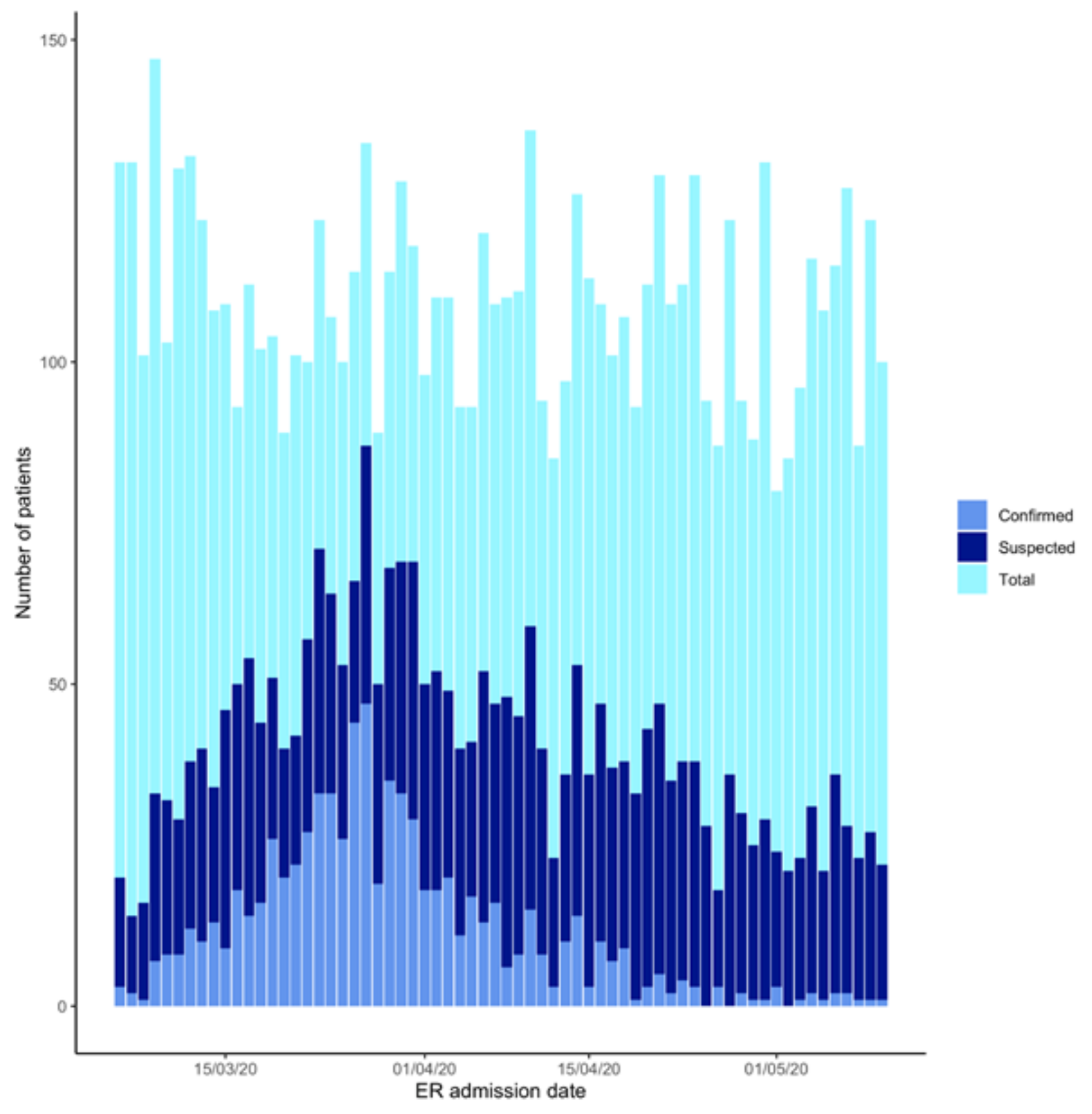

Figure 3

Number of patients admitted in EDs, suspected COVID-19 and confirmed COVID-19 by day admission. 

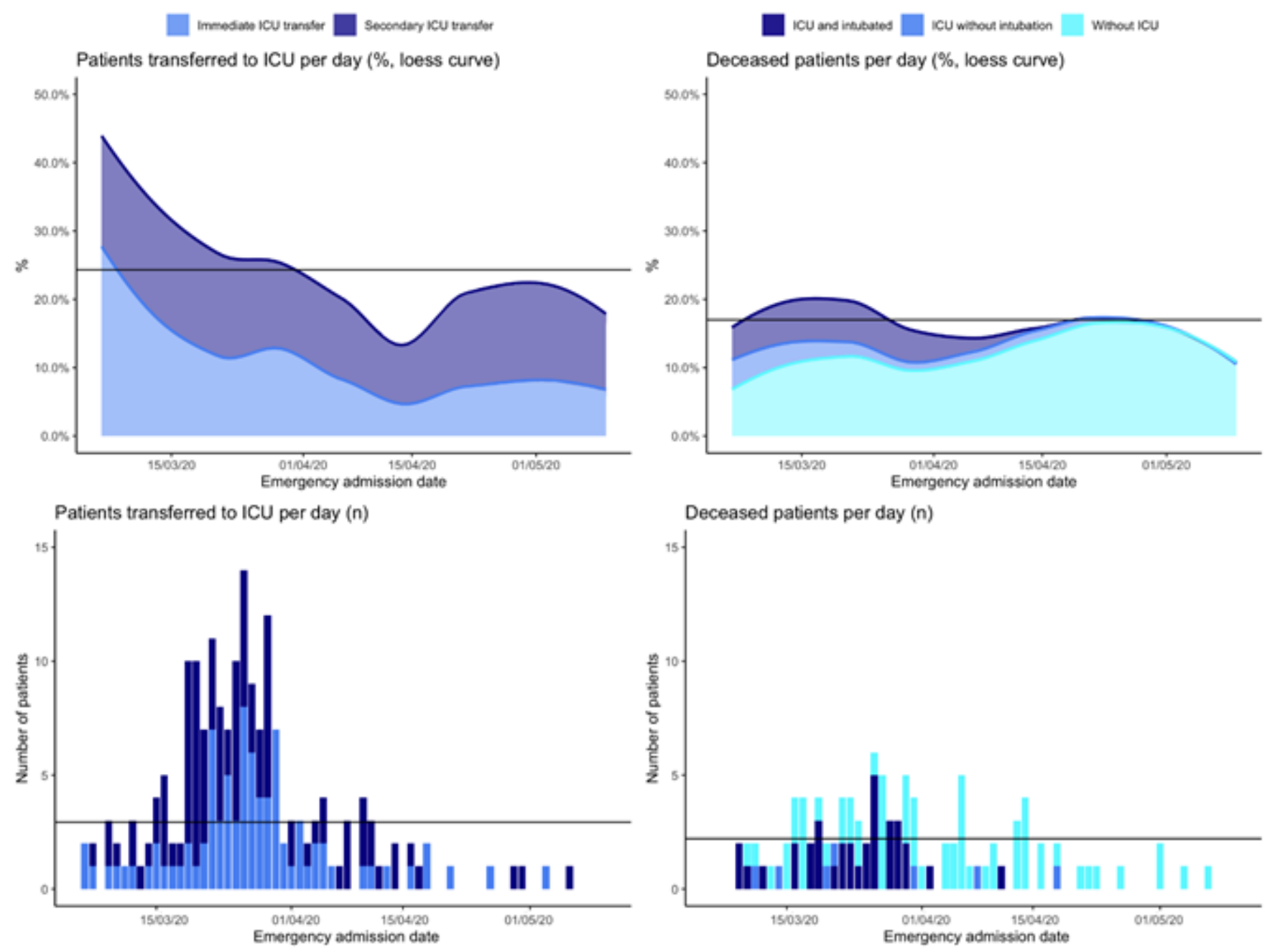

Figure 4

Comparative evolutions of ICU transfers (primary and secondary) and deaths depending on the day of ED admissions among COVID-19 positive patients (proportion (LOESS curve) and effective, with the average over the whole period represented by the black horizontal line) 


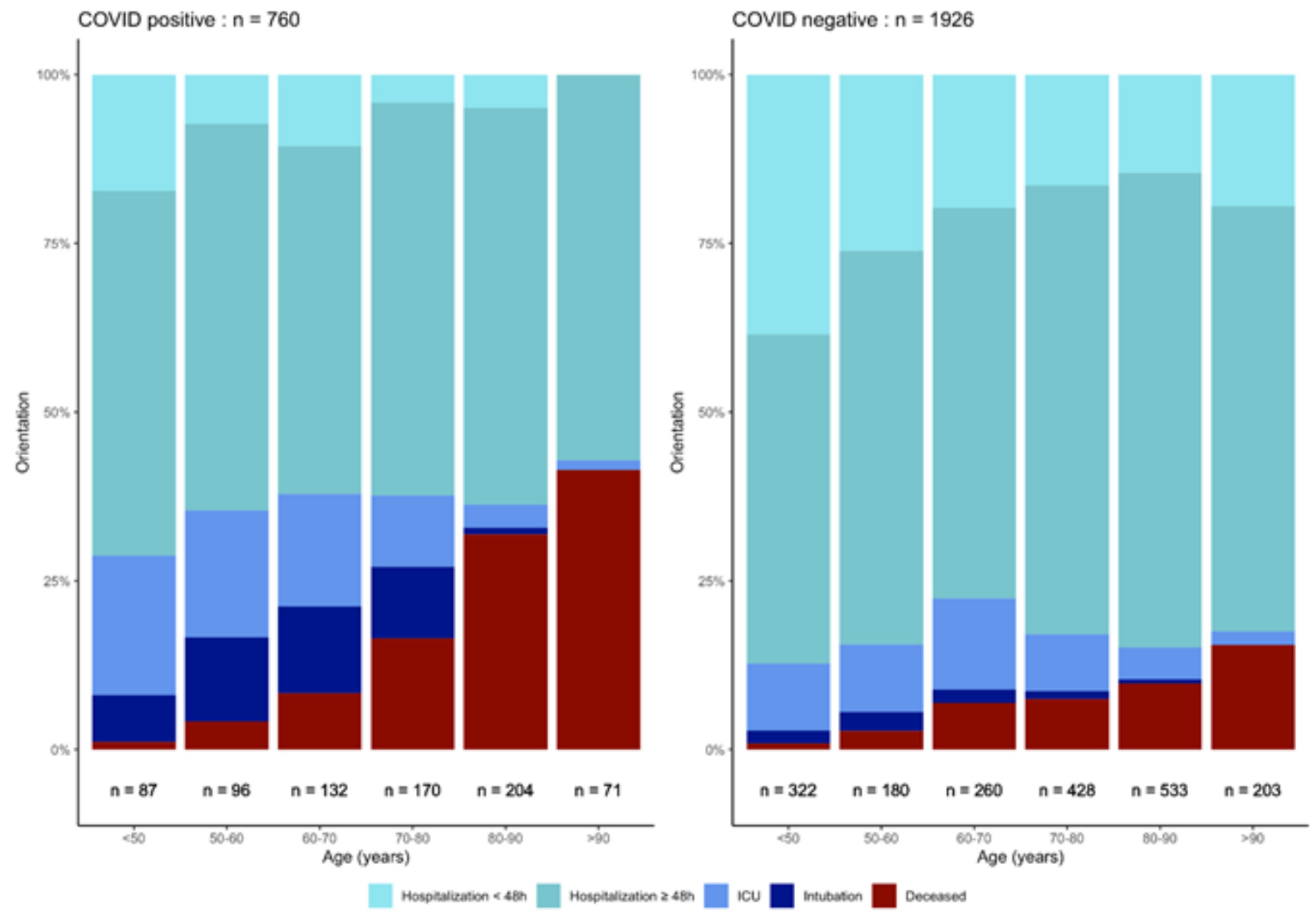

Figure 5

Outcome of COVID-19 positive and COVID-19 negative patients according to their age

\section{Supplementary Files}

This is a list of supplementary files associated with this preprint. Click to download.

- Supplementalmaterielfinal.docx 